\title{
Correlation of Physical Activity Level with Physical Fitness and Respiratory Function amongst Undergraduates
}

\author{
Nor Azura Azmi ${ }^{1}{ }^{*}$, Nur Tasnim Ahmad Zaki ${ }^{1}$, Mun Chun Kong ${ }^{1}$, \\ Nor Najwatul Akmal Ab Rahman ${ }^{2}$ and Asfarina Zanudin ${ }^{1}$ \\ ${ }^{I}$ Physiotherapy Programme, Centre for Rehabilitation and Special Needs Studies, \\ Faculty of Health Science, Universiti Kebangsaan Malaysia, Kuala Lumpur, Malaysia \\ ${ }^{2}$ Physiotherapy Programme, Cyberjaya University College of Medical Sciences, Selangor, Malaysia
}

('Corresponding author's e-mail: nazura.azmi@ukm.edu.my)

Received: 22 May 2020, Revised: 24 May 2021, Accepted: 26 May 2021

\begin{abstract}
Information regarding correlations between physical activity (PA) level with physical fitness (PF) and respiratory function (RF) amongst undergraduates is limited. We aimed to determine the difference in PA level, PF and RF between genders amongst undergraduates. In this cross-sectional study, we recruited 62 undergraduates, with mean age of $22.09 \pm 1.13$ years, from the Kuala Lumpur Campus, University Kebangsaan Malaysia. PA level was evaluated using the International Physical Activity Questionnaire (IPAQ) and expressed as metabolic equivalents (METs). PF was evaluated using a hand-grip strength test and a 6-minute walk distance (6MWD) test. RF, which included FEV1, FVC and FEV1/FVC, was measured using a spirometer. About 45.16 and $40.33 \%$ of undergraduates had high to moderate levels of physical activity, respectively. Males had significantly higher scores of METs compared to females, with $p<0.01$. Males had significantly higher hand-grip strength compared to females, with $p<0.001$. Higher $\mathrm{FEV}_{1}$ and $\mathrm{FVC}$ were found in males in comparison to their counterparts, with $p<0.001$. Females had significantly higher $\mathrm{FEV}_{1} / \mathrm{FVC}$ compared to males, with $p<0.01$. There were significant correlations between PA level with left hand-grip strength $(r=0.364, p<0.01)$, right hand-grip strength $(r=0.264, p$ $<0.05), \operatorname{FEV}_{1}(r=0.423, p<0.01)$, and FVC $(r=0.452, p<0.01)$. Our findings suggest that an increase in physical activity level may lead to an increase in physical fitness and respiratory function. Higher levels of physical activity should be promoted among healthy young adults for improved physical fitness and respiratory function during their study at universities.
\end{abstract}

Keywords: Physical activity, Physical fitness, Respiratory function, Undergraduate students, Spirometry, Hand-grip strength

\section{Introduction}

The World Health Organization (WHO) defines physical activity as any body movement that is produced by the skeletal muscle which consumes energy [1]. It is recommended for adults aged 18 to 64 years to do at least 150 min of moderate intensity of aerobic activity per week and strengthening exercises for large muscle groups for at least twice a week to stay physically active [1]. Physical activity includes structured and planned exercise, such as aerobic sessions or resistance and flexibility training, that can help improve and maintain cardiovascular fitness [2]. Additionally, physical activity can reduce study related-fatigue, stress and tension from academic responsibilities amongst students by improving their sleep quality and cognitive abilities $[3,4]$. It is suggested that physical activities could improve academic performance despite tight timetables, heavy workloads, gender, and nationality [5].

Although there are many benefits of performing physical activity and exercise, the prevalence of physical inactivity is increasing nowadays. Globally, in 2016, the prevalence of insufficient physical activity was at $27.5 \%$, which included $23 \%$ of men and $32 \%$ of women aged 18 years and over [6]. Over the past 15 years, levels of insufficient activity did not improve, as percentages of the world population with insufficient activity were constant from $2001(27.5 \%)$ to 2016 (28.5\%) [6]. In 2012, Malaysia had been listed as one of the top 10 physically inactive countries in South East Asia, with about $61.4 \%$ of Malaysian age 15 and above was considered inactive [7]. The Malaysian Adult Nutrition Survey reported that $36.9 \%$ of Malaysian adults aged 18 years and over were found to be physically 
inactive [8]. Malaysian adults were reported to have minimal walking activity, at only $9.5 \%$ per day, and climbing of stairs was at $0.1 \%$ per day, yet they spent most of their time, $74 \%$ per day, in sedentary activities such as lying down or sleeping [9]. This showed that most Malaysian adults choose the sedentary lifestyle, and it has become an important public health concern in Malaysia. Noncommunicable diseases and obesity has also risen dramatically over the past 30 years due to increase of physical inactivity amongst Malaysian adults $[10,11]$. Therefore, this could increase the mortality rate and the number impacted by other diseases such as cancer, diabetes mellitus, and osteoporosis [12]. A study in one of the Malaysian public universities revealed that the majority of the undergraduate students were physically active $(74.1 \%)$ [13]. However, this physical activity was believed to decline following graduation, as the young adults transition into the early phase of adulthood [14,15]. Hence, the low prevalence of participation in physical activity among Malaysian adults.

Physical activity is associated with physical fitness [16]. Physical fitness can be measured through several outcome measures of cardiorespiratory fitness, muscular strength, muscular endurance, body composition and flexibility [17]. It is recommended to use the 6MWT, the hand-grip test, and the IPAQ as measurements for the physical fitness of an individual [18]. Physical activity has positive influence on cardiovascular and respiratory functions [19]. Physical activity requires regular forceful inhalation and exhalation for a prolonged period, which indirectly leads to improved respiratory muscle strength [19]. Increased strength in respiratory muscle will further improve an individual's respiratory function parameters, including force expiratory volume in $1 \mathrm{~s}\left(\mathrm{FEV}_{1}\right)$, forced vital capacity $(\mathrm{FVC})$, and $\mathrm{FEV}_{1} / \mathrm{FVC}$ percentage [20].

There is an association between physical activity level with physical fitness and respiratory function. Only 2 studies found that there were significant correlations between physical activity and respiratory function amongst university students in the Middle East and healthy prepubescent children in European country, respectively [21,22]. Therefore, there is a paucity of studies regarding the correlation between physical activity level with physical fitness and respiratory function among undergraduates, specifically in Malaysia. It is important to assess the current physical activity of university students, since there is a low prevalence of physical activity participation among Malaysian adults. Hence, we aimed to explore the correlation between physical activity level with physical fitness and respiratory function among undergraduates at the Universiti Kebangsaan Malaysia (UKM).

\section{Materials and methods}

\section{Study participants}

Sixty-two participants from the Kuala Lumpur Campus, Universiti Kebangsaan Malaysia, were recruited in this study using convenience sampling. Participants included in the study were undergraduate students aged between 18 - 25 years old who were able to understand English. Students who were smokers or ex-smokers, and those whom self-reported of having health conditions such as pulmonary diseases, heart diseases, uncontrolled hypertension, diabetes, obesity or musculoskeletal injuries, were excluded from this study. The sample size was calculated using G-power software version 3.1.9.2. The confidence interval used was 0.05 , with power of 0.80 . Value of correlation coefficient, $r=0.57$ (moderate correlation), was referred to from a previous study which evaluated the relationship of physical activity level with 6MWD [23]. An optimal sample size was calculated to be 62 participants.

\section{Study design and procedure}

This correlational study was conducted to evaluate the correlation of physical activity level using the IPAQ with physical fitness and respiratory function among undergraduates. Assessment of physical fitness includes a 6MWD and hand-grip strength, while respiratory function parameters include $\mathrm{FEV}_{1}$, $\mathrm{FVC}$ and $\mathrm{FEV}_{1} / \mathrm{FVC}$. Ethical approval was granted from the Research Ethics Committee, Universiti Kebangsaan Malaysia, in February 2018 (Ethical code: NN-2018-064). Data collection was conducted from March to June 2018 at the Physical Therapy Laboratory of the Physiotherapy Programme, Faculty of Health Sciences, UKM. Informed consent was obtained from the participants prior to the commencement of data collection. Demographic data, such as age, gender, race, weight and height, were recorded. All participants completed a self-administered IPAQ questionnaire prior to their respiratory function assessment. After completing 3 readings of respiratory function test using spirometry, they were asked to rest for $5 \mathrm{~min}$. Then, participants were assessed with a hand-grip strength test, starting with their non-dominant hand, with a 1-min rest in between each tests. This test was repeated 3 times on each side. Finally, they were required to do 6MWT to complete the study assessments. All the data were recorded in the assessment form. 
Participants were weighed using an electronic scale that was calibrated before each measurement session without shoes. Height was assessed using a fixed wall-scale measuring device. Then, body mass index (BMI) of each participants was calculated as weight in kilogram $(\mathrm{kg})$ per height in meter square $\left(\mathrm{m}^{2}\right)$.

The IPAQ short version was used to measure the level of physical activity within 7 days. It has good test-retest reliability of $r=0.88$ [24], and strong construct validity of $r=0.93$ with accelerometer [25]. The IPAQ consists of 3 specific types of activities, which are walking, moderate intensity, and vigorous intensity [26]. The items in the short IPAQ form were organized separately into 3 categories of scores related to walking, moderate-intensity, and vigorous-intensity activity. The total score was calculated by the summation of duration (in minutes) and frequency (days) of walking, moderate-intensity, and vigorous-intensity activities. The duration and frequency of each variable were converted into metabolic equivalent minutes per week (METs-minute/week) scores based on the respective formula. The IPAQ classified the physical activity into 3 categories, which were low, moderate, and high physical activity, according to the individuals' activities in a week.

Spirometry was used for pulmonary function test to measure $\mathrm{FEV}_{1}, \mathrm{FVC}$ and $\mathrm{FEV}_{1} / \mathrm{FVC}$, according to the guidelines of the American Thoracic Society [27]. This pulmonary function test was conducted by an expert researcher who had expertise using the spirometry Cosmed Pony FX, Rome, Italy. Participants were requested to sit upright comfortably on a chair with their head slightly elevated and nose clip attached. Then, they were asked to take a maximum inspiration and expiration through a mouthpiece. Spirometry test was done for 3 times and the average reading was calculated in this study.

Hand-grip strength test was done using a hand dynamometer (Jamar hydraulic hand dynamometer) to assess physical fitness that related to muscular strength. The test was done in a sitting position with the shoulders adducted, elbows flexed at $90^{\circ}$, and forearms in a neutral position, and the participant was asked to grip as hard as possible and hold for $3 \mathrm{~s}$. This test is considered the easiest method to obtain general muscle strength and function [28,29]. Jamar hydraulic hand dynamometer has excellent reliability $(\mathrm{ICC}=0.98)$ and construct validity of $r=0.99$ (very high correlation) with Rolyan dynamometers [30,31].

Physical fitness related to functional endurance was assessed using the 6MWT, according to the guidelines of the American Thoracic Society [32]. 6MWT was preferred over another test (3-min step test) because it is less stressful and better at providing performance-based measures for individuals of all ages [33]. Additionally, 6MWT is a practical and simple test to conduct and is more reflective of daily activities compared to other walking tests [34]. 6MWT has an excellent reliability $(\mathrm{ICC}=0.95)$ and construct validity of $r=0.5$ (moderate correlation) with an Astrand Cycle Ergometer [18].

\section{Data analysis}

Data were analyzed using Statistical Package for Social Science (SPSS) software version 23. Demographic data were analyzed using descriptive statistics and were expressed in frequency $(n)$, percentage (\%), mean, and standard deviation (SD). Non-parametric tests were used to analyze the data, due to the normality assumption being violated. Mean differences between gender across the variables were analyzed using Mann-Whitney test. Correlations between physical activity level with physical fitness and respiratory function were analyzed using the Spearman correlation test. Statistical significance level was set at $5 \%, p<0.05$.

\section{Results and discussion}

Sixty-two undergraduates, with mean age of $22.09 \pm 1.13$ years, participated in the study. The majority of the participants were female, with 38 students $(61.29 \%)$. Most of the participants were Chinese $(n=47,75.8 \%)$, and the rest were Malay $(n=15,24.2 \%)$. Generally, $45.16 \%(n=28)$ and $40.33 \%(n=25)$ of participants had high to moderate levels of physical activity, respectively. There was a small percentage of students at $14.51 \%(n=9)$ who had low levels of physical activity (Figure 1). Figure 1 shows that the majority of female undergraduates had a moderate level of physical activity $(n=$ $19)$, while most males had a high level of physical activity $(n=17)$. 


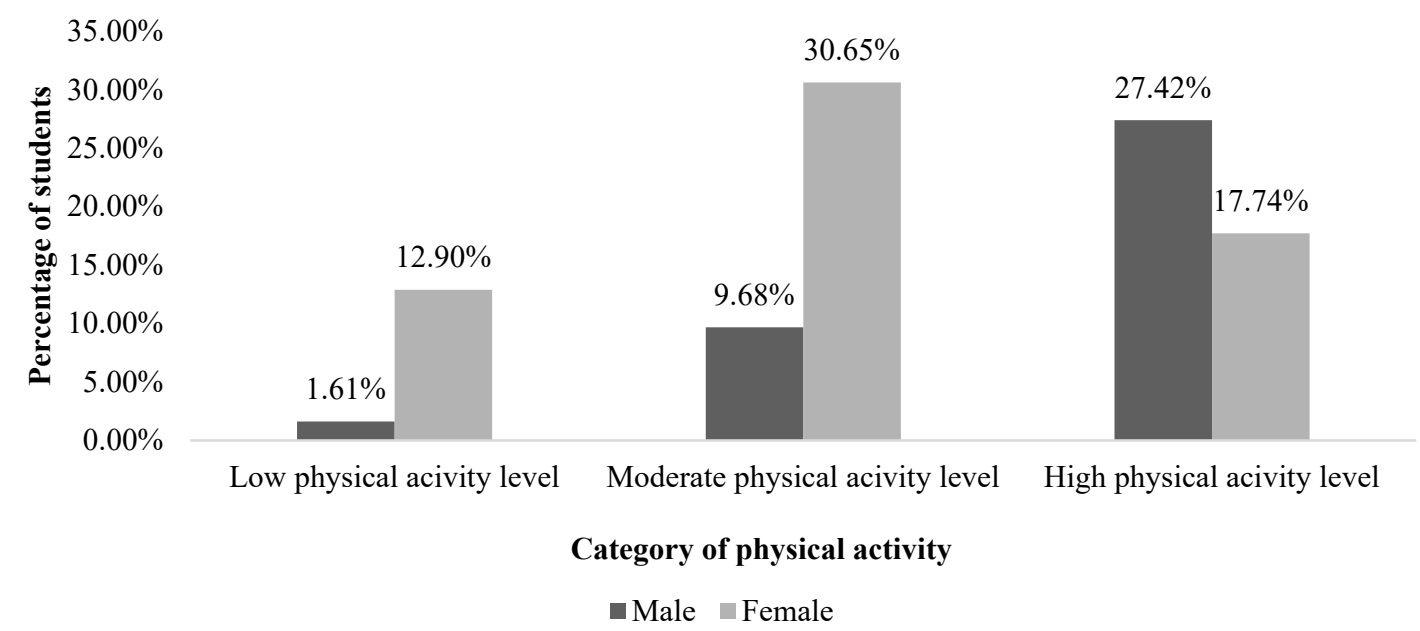

Figure 1 Scores of the IPAQ among participants.

Table 1 shows the characteristics of participants according to gender. All participants had normal body weight, with the total mean of body mass index (BMI) at $21.79 \pm 3.07 \mathrm{kgm}^{2}$ (Table 1). Male undergraduates scored significantly higher METs-minutes per week of total IPAQ compared to females, with $p<0.01$ (Table 1). Table 1 shows the difference between the left and the right hand in the total of the hand-grip strength scores. Males had significantly higher hand-grip strength for both the left and the right hand compared to females undergraduates, with $p<0.001$. Likewise, scores of FEV ${ }_{1}$ and FVC were higher in males than in females, with $p<0.001$ (Table 1). On the contrary, females had higher $\mathrm{FEV}_{1} / \mathrm{FVC}$ score than males, with $p<0.01$ (Table 1). No significant difference was observed between males and females in 6MWD scores (Table 1).

Table 1 Characteristics of participants according to gender.

\begin{tabular}{|c|c|c|c|}
\hline Characteristics & $\begin{array}{l}\text { Total }(n=62) \\
\text { Mean (SD) }\end{array}$ & $\begin{array}{l}\text { Male }(\mathrm{n}=24) \\
\text { Mean }(\mathrm{SD})\end{array}$ & $\begin{array}{l}\text { Female }(\mathbf{n}=38) \\
\quad \text { Mean }(\text { SD) }\end{array}$ \\
\hline Age & $22.09 \pm 1.13$ & $21.59 \pm 1.18$ & $22.39 \pm 1.05$ \\
\hline Body Mass Index $\left(\mathrm{kg} / \mathrm{m}^{2}\right)$ & $21.79 \pm 3.07$ & $21.26 \pm 2.98$ & $22.10 \pm 3.11$ \\
\hline $\begin{array}{l}\text { Total IPAQ score } \\
\text { (METs- minutes/week) }\end{array}$ & $2704.67 \pm 2557.364$ & $3722.55 \pm 3111.47$ & $2115.37 \pm 1990.30^{*}$ \\
\hline $\begin{array}{l}\text { High physical activity } \\
\text { (METs- minutes/week ) }\end{array}$ & $4790.85 \pm 2583.60$ & $4814.36 \pm 1572.90$ & $4773.6 \pm 3186.17$ \\
\hline $\begin{array}{l}\text { Moderate physical activity (METs- } \\
\text { minutes/week ) }\end{array}$ & $1363.80 \pm 716.86$ & $1657.50 \pm 1235.56$ & $1271.05 \pm 472.55$ \\
\hline $\begin{array}{l}\text { Low physical activity } \\
\text { (METs- minutes/week) }\end{array}$ & $405.56 \pm 327.33$ & 347 & $409.50 \pm 349.22$ \\
\hline $6 \mathrm{MWD}(\mathrm{m})$ & $544.07 \pm 68.17$ & $547.29 \pm 70.49$ & $542.21 \pm 67.67$ \\
\hline Left hand-grip strength $(\mathrm{kg})$ & $31.00 \pm 7.90$ & $38.23 \pm 7.33$ & $26.82 \pm 4.47 * *$ \\
\hline Right hand-grip strength (kg) & $33.29 \pm 9.10$ & $41.33 \pm 8.48$ & $28.64 \pm 5.53^{* *}$ \\
\hline $\mathrm{FEV}_{1}(1)$ & $3.02 \pm 0.51$ & $3.57 \pm 0.34$ & $2.75 \pm 0.33^{* *}$ \\
\hline FVC (1) & $3.32 \pm 0.67$ & $3.98 \pm 0.47$ & $2.88 \pm 0.45^{* *}$ \\
\hline $\mathrm{FEV}_{1} / \mathrm{FVC}(\%$ ratio $)$ & $90.96 \pm 0.57$ & $89.69 \pm 0.41$ & $95.48 \pm 0.49^{*}$ \\
\hline
\end{tabular}

**Mann-Whitney test with $p<0.001$

* Mann-Whitney test with $p<0.01$ 
The Spearman correlation test revealed that there were moderate significant correlations between physical activity level with $\mathrm{FEV}_{1}$ and FVC, with $p<0.01$ (Table 2). Other than that, weak significant correlations between physical activity level with the left $(p<0.01)$ and right hand-grip strength $(p<0.05)$ were found in this study (Table 2). Nevertheless, no significant correlations between physical activity level with $\mathrm{FEV}_{1} / \mathrm{FVC}$ and 6MWD were found, with $p>0.05$ (Table 2).

Table 2 Correlations of physical activity level with physical fitness (hand-grip strength and 6MWD) and respiratory function (FEV1, FVC and FEV1/ FVC).

\begin{tabular}{ccl}
\hline \multirow{2}{*}{ Correlation } & \multicolumn{2}{c}{ IPAQ } \\
\cline { 2 - 3 } & $r$ & $p$ \\
\hline Left hand-grip strength & 0.364 & $0.004^{* *}$ \\
Right hand-grip strength & 0.264 & $0.041^{*}$ \\
6MWD & 0.160 & 0.223 \\
FEV1 & 0.423 & $0.002^{* *}$ \\
FVC & 0.452 & $0.001^{* *}$ \\
FEV1/ FVC & 0.180 & 0.198 \\
\hline
\end{tabular}

$* *$ Correlation is significant at the 0.01 level

*Correlation is significant at the 0.05 level

This study explored correlation between physical activity with physical fitness and respiratory function amongst undergraduate students at the Kuala Lumpur Campus, UKM. The majority of the participants had high levels of physical activity, followed by moderate levels, which may reflect that they are physically active. This finding is consistent with a previous study, which found that $70 \%$ of participants aged between 18 to 29 years had reached the recommendation of 30 min per day of moderate or greater physical activity intensity among the Portuguese population [35]. A previous Malaysian study reported that the younger population in Malaysia was more active compared to the older adult population [36]. However, our finding is contrary to that of a previous study, which revealed that the majority of university students in Terengganu, Malaysia, walked less than 5000 steps on average count per day, which can be classified as a sedentary lifestyle [37]. All students in the Kuala Lumpur Campus, UKM, were from a Health Science course background. Therefore, it is believed that Health Science students had higher awareness of their health status and maintained healthy lifestyles compared to those undergoing other courses [38,39].

We found that male students had higher METs-minutes per week of total IPAQ compared to females, which indicated that males were more physically active. This finding is in agreement with the finding from a previous study, which reported that male students from a university in the Southern United States had higher physical activity compared to female students [40]. Additionally, our finding corroborates the findings of 2 previous Malaysian studies [37,41], which also found that Malaysian male undergraduate students were more physically active compared to females. It was discovered that lack of encouragement from school and family members led to less participation in physical activity among female students [42]. In addition, it was reported that enjoyment in engaging with physical activity among males was higher compared to females [42]. Furthermore, different preferences of physical activities between genders, in which males were more likely to enjoy various sports game activities such as basketball, skateboarding, badminton, or football, and females only tended to jog, may have influenced their physical activity levels [43]. Hence, these are the reasons that led to increase in physical activity participation among male students.

Our study found that there were weak significant correlations between physical activity levels with left and right hand-grip strength. These findings are in agreement a with previous study, which found that there was correlation between hand-grip strength and physical activity level amongst musculoskeletal patients [44]. The explanation for this may be due to higher physical activity participation leading to subsequently improved muscular strength, which is associated with higher hand-grip strength [2,45]. In 
addition, there were significant moderate correlations between physical activity and respiratory function parameters, which are $\mathrm{FEV}_{1}$ and FVC, found in our study. Similar findings were gathered in a study that was conducted among university students in Saudi Arabia [17]. Two previous studies also found significant correlations between physical activity and lung function parameters [46,47]. Forceful breathing, which comprise inspiration and expiration for a long duration during exercise, might promote a rise in respiratory muscle strength [48]. Additionally, physical activity might increase maximal shortening of inspiratory muscles, which further leads to an increase in respiratory function parameters [19]. A previous study found that participants that maintained an active lifestyle showed improvements in their $\mathrm{FEV}_{1}$ and FVC for 50 and $70 \mathrm{~mL}$, respectively [49]. In contrast, participants that maintained a sedentary lifestyle showed reduction in the respiratory parameters for 30 and $20 \mathrm{~mL}$ in $\mathrm{FEV}_{1}$ and $\mathrm{FVC}$, respectively. It was reported that $\mathrm{FEV}_{1}$ normally declines with age, and that individuals experience a loss of about one third liters of their $\mathrm{FEV}_{1}$ per decade [50]. However, another study reported that there was slightly slower regression of $\mathrm{FEV}_{1}$ in participants who were physically active compared to sedentary participants [51]. A previous study reported that young sedentary lifestyle participants have a high risk for reduction in respiratory parameters and, thus, increase the risk of developing chronic pulmonary disease in later stages of life [47]. Hence, prescribing appropriate physical activity intervention might delay the deterioration in respiratory function among the young population. We found no correlations between physical activity level with $6 \mathrm{MWD}$ and $\mathrm{FEV}_{1} / \mathrm{FVC}$ in the present study. Therefore, no relationship between physical activity with $6 \mathrm{MWD}$ and $\mathrm{FEV}_{1} / \mathrm{FVC}$ were observed amongst undergraduate students. However, this finding warrants further investigation.

There are a few limitations to this study that should be considered in order to appropriately interpret our study findings. This study covered a small sample size, and the participants were recruited from a single population of undergraduates at the Kuala Lumpur Campus, UKM. Hence, the findings might not be able to be used to generalize the Malaysian undergraduate student population. However, future study should include a larger sample size and participants from various universities within Malaysia to obtain more representative and generalization findings. Instruments used in this study, especially spirometry machine and hand dynamometer, might be different from other studies in terms of their models and manufacturers; hence, careful interpretation should be considered when comparing the findings with others. All instruments were carefully calibrated before each measurement session during data collection by the expert researcher to ensure that there would be no instrumental error and to enhance the accuracy of the measurements.

\section{Conclusions}

In conclusion, the majority of undergraduate students at the Kuala Lumpur Campus, UKM, were physically active. Most of them were engaged with moderate to high levels of physical activity categories. There were significant correlations found between physical activity with the hand-grip strength and respiratory function parameters in this study. Our study findings suggest that an increase in physical activity level may lead to an increase in physical fitness and respiratory function. Therefore, higher levels of physical activity engagement should be promoted among healthy young adults as a healthy lifestyle for enhanced physical fitness and respiratory function during their study at universities.

\section{Acknowledgements}

The authors are grateful to the undergraduate students from the Universiti Kebangsaan Malaysia who participated in this study.

\section{References}

[1] World Health Organization. Global recommendations on physical activity for health. World Health Organization, Geneva, 2010.

[2] CE Garber, B Blissmer, MR Deschenes, BA Franklin, MJ Lamonte, IM Lee, DC Nieman and DP Swain. Quantity and quality of exercise for developing and maintaining cardiorespiratory, musculoskeletal, and neuromotor fitness in apparently healthy adults: Guidance for prescribing exercise. Med. Sci. Sports Exerc. 2011; 43, 1334-59.

[3] JDDVries, MLMV Hooff, SAE Geurts and MAJ Kompier. Exercise as an intervention to reduce study-related fatigue among university students: A two-arm parallel randomized controlled trial. PLoS One. 2016; 11, e0152137. 
[4] K Kamarudin and MS Omar-Fauzee. Attitudes toward physical activities among college students. Pak. J. Psychol. Res. 2007; 22, 43-54.

[5] MA Elmagd, AH Mossa, MM Sami, TS El-Marsafawy, O Al-Jadaan and MSE Mudawi. The impact of physical activity on the academic performance among medical and health sciences students: A cross sectional study from RAKMHSU - Ras Alkhaimah-UAE. Int. J. Phys. Educ. Sport Health $2015 ; 2,92-5$.

[6] R Guthold, GA Stevens, LM Riley and FC Bull. Worldwide trends in insufficient physical activity from 2001 to 2016: A pooled analysis of 358 population-based surveys with 1.9 million participants. Lancet 2018; 6, E1077-E1086.

[7] PC Hallal, LB Andersen, FC Bull, R Guthold, W Haskell and U Ekelund. Global physical activity levels: Surveillance progress, pitfalls, and prospects. Lancet 2012; 380: 247-257.

[8] Institute for Public Health. National health and morbidity survey 2014: Malaysian adult nutrition survey (MANS). Institute for Public Health, Ministry of Health, Kuala Lumpur, 2014.

[9] BKP Jr, MY Safiah, A Tahir, MDS Haslinda, NS Norazlin, AK Norimah, WW Manan, K Mirnalini, MS Zalilah, MY Azmi and S Fatimah. Physical activity pattern and energy expenditure of Malaysian adults: Findings from the Malaysian Adult Nutrition Survey (MANS). Malays. J. Nutr. 2010; 16, 13-37.

[10] MNN Safiza, GL Khor, S Suzana, CC Kee, H Jamaiyah, A Geeta, R Rahmah, NF Wong, ZA Ahmad, AR Jamaluddin, AT Ruzita and YA Faudzi. The Third National Health and Morbidity Survey (NHMS III) 2006: Nutritional status of adults aged 18 years and above. Malays. J. Nutr. 2008; 14, S1-S87.

[11] TC Lian, G Bonn, YS Han, YC Choo and WC Piau. Physical activity and its correlates among adults in Malaysia: A cross-sectional descriptive study. PLoS One 2016; 11, e0157730.

[12] DER Warburton, CW Nicol and SSD Bredin. Health benefits of physical activity: The evidence. Can. Med. Assoc. J. 2006; 174, 801-9.

[13] JA Stephen, RB Elias, BRA Gilbert, NABM Farid, DTM Han and SPA Atang. Physical activity among unimas undergraduates. Int. J. Cur. Res. Rev. 2021; 13, S81-S88.

[14] N Salamuddin and MT Harun. Physical activity index among Malaysian youth. Asian Soc. Sci. 2013; 9, 99-104.

[15] D Sigmundová, F Chmelík, E Sigmund, D Feltlová and K Frömel. Physical activity in the lifestyle of Czech university students: Meeting health recommendations. Eur. J. Sport Sci. 2013; 13, 744-50.

[16] JL Wang. The association between physical fitness and physical activity among Chinese college students. J. Am. Coll. Health 2019; 67, 602-9.

[17] AC King, KE Powell and WE Kraus. The US physical activity guidelines advisory committee report-introduction. Med. Sci. Sports Exerc. 2019; 51,1203-5.

[18] AT Tveter, HD Dagfinrud, T Moseng and I Holm. Measuring health-related physical fitness in physiotherapy practice: Reliability, validity, and feasibility of clinical field tests and a patientreported measure. J. Orthop. Sports Phys. Ther. 2014; 44, 206-16.

[19] SS Fatima, R Rehman, Saifullah and Y Khan. Physical activity and its effect on forced expiratory volume. J. Pak. Med. Assoc. 2013; 63, 310-2.

[20] V Akhade and NS Muniyappanava. The effect of running training on pulmonary function tests. Natl. J. Physiol. Pharm. Pharmacol. 2014; 4, 168-70.

[21] AS Khashaba. Effect of levels of physical activity on pulmonary function of male Saudi university students. Int. J. Sports Sci. 2015; 5, 209-12.

[22] C Nourry, F Deruelle, C Guinhouya, G Baquet, C Fabre, F Bart, S Berthoin and P Mucci. Highintensity intermittent running training improves pulmonary function and alters exercise breathing pattern in children. Eur. J. Appl. Physiol. 2005; 94, 415-23.

[23] AJ Serra, PDTCD Carvalho, F Lanza, CDA Flandes, SC Silva, FS Suzuki, DS Bocalini, E Andrade, C Casarin and JA Silva. Correlation of six-minute walking performance with quality of life is domain-and gender-specific in healthy older adults. PLoS One 2015; 10, e0117359.

[24] CL Craig, AL Marshall, M Sjostrom, AE Bauman, ML Booth, BE Ainsworth, M Pratt, U Ekelund, A Yngve, JF Sallis and P Oja. International physical activity questionnaire: 12-country reliability and validity. Med. Sci. Sports Exerc. 2003; 35, 1381-95.

[25] MNMV Poppel, MJM Chinapaw, LB Mokkink, WV Mechelen and CB Terwee. Physical activity questionnaires for adults. Sports Med. 2010; 40, 565-600.

[26] International Physical Activity Questionnaire. Guidelines for data processing and analysis of the International Physical Activity Questionnaire (IPAQ) - short and long forms. 2005. 
[27] MR Miller, J Hankinson, V Brusasco, F Burgos, R Casaburi, A Coates, R Crapo, P Enright, CPMV D Grinten, P Gustafsson, R Jensen, DC Johnson, N Macintyre, R Mckay, D Navajas, OF Pedersen, R Pellegrino, G Viegi and J Wanger. Standardisation of spirometry. Eur. Respir. J. 2005; 26, 31938.

[28] M Aadahl, N Beyer, A Linneberg, BH Thuesen and T Jørgensen. Grip strength and lower limb extension power in 19-72-year-old Danish men and women: The health 2006 study. BMJ Open 2011; 1, e000192.

[29] RW Bohannon. Is it legitimate to characterize muscle strength using a limited number of measures? J. Strength Cond. Res. 2008; 22, 166-73.

[30] JV Bellace, D Healy, MP Besser, T Byron and L Hohman. Validity of the dexter evaluation system's Jamar dynamometer attachment for assessment of hand grip strength in a normal population. J. Hand Ther. 2000; 13, 46-51.

[31] V Mathiowetz. Comparison of Rolyan and Jamar dynamometers for measuring grip strength. Occup. Ther. Int. 2002; 9, 201-9.

[32] American Thoracic Society. ATS statement: Guidelines for the six-minute walk test. Am. J. Respir. Crit. Care Med. 2002; 166, 111-7.

[33] RW Bohannon, DJ Bubela, YC Wang, SS Magasi and RC Gershon. Six-minute walk tests. threeminute step test for measuring functional endurance. J. Strength Cond. Res. 2015; 29, 3240-4.

[34] S Solway, D Brooks, Y Lacasse and S Thomas. A qualitative systematic overview of the measurement properties of functional walk tests used in the cardiorespiratory domain. Chest 2001; 119, 256-70.

[35] F Baptista, DA Santos, AM Silva, J Mota, R Santos, S Vale, JP Ferreira, AM Raimundo, H Moreira and LB Sardinha. Prevalence of the Portuguese population attaining sufficient physical activity. Med. Sci. Sports Exerc. 2012; 44, 466-73.

[36] TC Lian, G Bonn, YS Han, YC Choo and WC Piau. Physical activity and its correlates among adults in Malaysia: A cross-sectional descriptive study. PLoS One. 2016; 11, e0157730.

[37] NAM Yusoff, S Ganeson, KF Ismail, H Juahir, MR Shahril, LP Lin, A Ahmad, SW Wafa, S Harith and R Rajikan. Physical activity level among undergraduate students in Terengganu, Malaysia using pedometer. J. Fund. Appl. Sci. 2018; 10, 512-22.

[38] SK Tadakamadla, D Kriplani, V Shah, J Tadakamadla, H Tibdewal, P Duraiswamy and S Kulkarni. Oral health attitudes and behaviour as predisposing factor for dental caries experience among health professional and other professional college students of India. Oral Health Prev. Dent. 2010; 8, 195202.

[39] K Peltzer, S Pengpid, TK Yung, HA Skhiri and R Rehman. Comparison of health risk behavior, awareness, and health benefit beliefs of health science and non-health science students: An international study. Nurs. Health Sci. 2016; 18, 180-7.

[40] RP Joseph, KE Royse, TJ Benitezand and DW Pekmezi. Physical activity and quality of life among university students: Exploring self-efficacy, self-esteem, and affect as potential mediators. Qual. Life Res. 2014; 23, 659-67.

[41] R Rajappan, K Selvaganapathy and L Liew. Physical activity level among university students: A cross sectional survey. Int. J. Physiother. 2015; 3, 1336-43.

[42] RM Telford, RD Telford, LS Olive, T Cochrane and R Davey. Why are girls less physically active than boys? Findings from the look longitudinal study. PLoS One. 2016; 11, e0150041.

[43] N Salamudin and MT Harun. Physical activity index among Malaysian youth. Asian Soc. Sci. 2013; 9, 99-104.

[44] K Norman, N Stobäus, MC Gonzalez, JD Schulzke and M Pirlich. Hand grip strength: Outcome predictor and marker of nutritional status. Clin. Nutr. 2011; 30, 135-42.

[45] ME Nelson, WJ Rejeski, SN Blair, PW Duncan, JO Judge, AC King, CA Macera and C CastanedaSceppa. Physical activity and public health in older adults: Recommendation from the American College of Sports Medicine and the American Heart Association. Med. Sci. Sports Exerc. 2007; 39, 1435-45.

[46] A Luzak, S Karrasch, B Thorand, D Nowak, R Holle, A Peters and H Schulz. Association of physical activity with lung function in lung-healthy German adults: Results from the Kora FF4 study. BMC Pulm. Med. 2017; 17, 215.

[47] A Azad, R Gharakhanlou, A Niknam and A Ghanbari. Effects of aerobic exercise on lung function in overweight and obese students. Tanaffos 2011; 10, 24-31

[48] RG Thaman, A Arora and R Bachhel. Effect of physical training on pulmonary function tests in border security force trainees of India. J. Life Sci. 2010; 2, 11-5. 
[49] J Garcia-Aymerich, P Lange, M Benet, P Schnohr and JM Anto. Regular physical activity modifies smoking-related lung function decline and reduces risk of chronic obstructive pulmonary disease: A population-based cohort study. Am. J. Respir. Crit. Care Med. 2007; 175, 458-63.

[50] S Solanki, P Mirdha and R Choudhary. A comparative study of pulmonary function in healthy male and female subjects of western Rajasthan. Sch. J. Appl. Med. Sci. 2016; 4, 3398-401.

[51] BM Brumpton, A Langhammer, AH Henriksen, CA Camargo, Y Chen, PR Romundstad and XM Mai. Physical activity and lung function decline in adults with asthma: The Hunt Study. Respirology 2017; 22, 278-83. 